\title{
Determining Factors of the Effectiveness of IP-based Spin-offs: Comparing the Netherlands and the US
}

Rudi Bekkers ${ }^{1}$
Victor Gilsing
Marianne van der Steen $^{2}$

\begin{abstract}
In this paper we describe and analyse IP-based spin-offs as a relatively new phenomenon for transferring knowledge from science to industry. We argue that the effectiveness of this mechanism is subject to a complex array of institutional factors. These factors entail national, sectoral, regional and managerial institutions. Based on an indicative comparison between the Netherlands and the United States we find that is especially the combination of national and sectoral institutions that condition whether an IP-based spin-off is established in the first place, whereas regional and managerial institutions condition its subsequent chances of success. We finish by formulating some notions for public policy.
\end{abstract}

Keywords: industry-science relationships (ISR), spin-offs, technology transfer, university patenting

JEL Classification: O3, O32, O34, L2, L3, I28

\section{Introduction}

One of the basic assumptions of publicly financed research is that its results will be utilized and thus contribute to social-economic welfare. It is widely recognized that it does so. For the Netherlands it has been established that about $21 \%$ of all technological innovations are based on such public research (NOWT, 2000). However, there are still various obstacles to be overcome before the results of public research are actually utilized. This issue is at the heart of current discussions, both within EU and OECD member states, how results of public research can best be commercialized (EC, 2001; OECD, 2002; Ministry of Economic Affairs, 2004). A major question in this debate is how such technology transfer can best be achieved.

\footnotetext{
${ }^{1}$ ECIS, Eindhoven University of Technology

P.O. Box 513, 5600 MB, Eindhoven, The Netherlands

E-mail:r.n.a.bekkers@tm.tue.nl

${ }^{2}$ Economics Department, Delft University of Technology 5015, 2600 GA, Delft, The Netherlands
}

Apparently, there are various possible types of mechanisms for technology transfer, ranging from licenses, contract research, mobility of scientists, and technology roadmaps to publications of research results in the public domain. This paper focuses on one mechanism in particular, namely IP-based spin-offs.

IP-based spin-offs have recently emerged as a mechanism for technology transfer and build on two relevant phenomena for an effective transfer of technology, namely (1) IP protection at Public Research Institutes (PROs), ${ }_{1}^{1}$ and (2) the establishment of spin-offs. The first phenomenon of IP protection by PROs, such as taking out patents, may lead to utilization of inventions that would not have occurred without. The second phenomenon is the establishment of a new firm that is dedicated to the development of an invention into a new product or service. Such firms, usually referred to as spin-offs, focus on this generally risky development process that is often ignored by established firms. In addition, an intensive contact between the spin-off and its 'parent' PRO, may positively contribute to the successful development of the invention and hence to a wider diffusion of new technological knowledge. This paper focuses on the combination of these two phenomena, i.e. IP-based spin-offs from PROs.

Despite the recent interest for IP-based spinoffs, an in-depth understanding of their effectiveness as a mechanism for technology transfer is still underdeveloped. This seems in line with the partial view developed in most studies on technology transfer (Bozeman, 2000). In these studies there is a focus on one or a limited number of elements while abstracting from other possibly relevant factors (Jaffe, 2000; Jaffe and Lerner, 2001; Mowery et al., 2001; Colyvas et al., 2002; Cohen and Merrill, 2003; Di Gregorio and Shane, 2003; 
Nerkar and Shane, 2003; OECD, 2003; for an overview see Link et al., 2003). The aim of this paper therefore is to develop a more complete and structured understanding of those factors that determine the effectiveness of IP-based spin-offs as a mechanism for technology transfer. More specifically, we aim to understand which institutional factors create favorable conditions for establishing them in the first place, as well as which factors condition their subsequent chances of success.

This paper proceeds as follows. We first discuss the phenomenon of IP-based spin-offs more indepth and present some basic empirical facts on the Netherlands. This will be done in Section 2. In Section 3, we present our conceptual framework that helps us to understand the role of different institutional factors in conditioning the effectiveness of IP-based spin-offs. Furthermore, we discuss our methods of data collection. Following the logic of our conceptual framework, we then discuss and analyse our empirical findings on IP-based spin-offs in the Netherlands in the Sections 4-7. In Section 4, we discuss the role of national institutions and in Section 5 the role of sectoral institutions. In Section 6 we analyse the role of PROs, whereas in Section 7 we descend to the managerial level and discuss its influence. Finally, in Section 8, we conclude and discuss some notions for public policy. Although our main focus in this paper will be on the Netherlands, we will also provide information and findings on the US. The US can be considered as the benchmark in the field of industry-science relations (OECD, 2003), so that these US findings enable us to make some comparisons between both countries. Such a comparison provides us with an indication of the relative performance of the Netherlands with regard to IP-based spin-offs and enables us to obtain insights in how to improve their effectiveness.

\section{IP-based spin-offs in The Netherlands}

In this section we provide a general introduction to IP-based spin-offs, with a particular focus on the Netherlands. As IP-based spin-offs of PROs combine two phenomena, we make use of a definition that entails both these elements: (1) a new firm which start-up includes a novel technological knowledge that has recently been developed at a PRO, and, (2) where this knowledge is protected by an Intellectual Property Right (IPR) that is either licensed or transferred to the firm. Note that in this definition the direct involvement of (ex-)staff in the management of the spin-off firm is not necessarily required. By making this choice we differentiate from other definitions of spin-offs that stress such (ex-)staff involvement. This choice is informed by experiences in the US, which indicate that it is especially the category of firms with no direct staff involvement in the management of the organization, seems to have very promising prospects. Following this definition, we discuss in this section the various characteristics of this type of spin-off and its potential strengths, both from a PRO perspective and from a public policy perspective. Moreover, we present some basic empirical facts on IP-based spin-offs that have been established in the Netherlands.

\section{Potential strengths of IP-based spin-offs: a PRO perspective}

In the Netherlands we observe a clear trend of PROs that protect their inventions increasingly by making use of IPRs such as applying for patents, exercising copyrights and other forms. ${ }^{2}$ For instance, the average number of annual patent applications by Dutch universities has grown from four in 1981 to about 80 in 1998, while patenting at other PROs is also observed to be growing at a steady pace (Ministry of Economic Affairs, 2001). One reason for PROs to make use of IP protection is of particular relevance in the context of this paper: it facilitates the utilization of public-founded research results by firms, especially when substantial additional research is required in view of commercial application. Especially in this case, firms will only consider further development and engage in the associated investments if they have possibilities for protection against copying.

Other reasons for PROs to stimulate IP-based spin-offs is that they enable to retain and recruit staff, to induce closer ties with industry and to promote economic growth. These arguments in favor of IP-based spin-offs should be weighed against their potential disadvantages. A potential disadvantage is that it may have a negative effect on publication efforts by PRO staff. Other negative effects are that it may create a threshold, 
financial or otherwise, for firms to utilise research results. Moreover, it may create a monopoly in the hands of a single firm, especially in the case of an exclusive license. Finally, applying for and owning IPRs implies a costly and time-consuming process.

Apart from these IP related aspects, for PROs, the most important argument for spin-offs is to improve the effective transfer of technology. Attempts in the late 1980s to promote the commercial use of novel technological knowledge revealed that the process of technology transfer could be greatly facilitated, when not only the codified knowledge was exchanged but also the associated tacit knowledge, ideas and 'creative energy' of the involved researchers (Wintjes et al., 2002). This can best be achieved by an involvement of the PRO researchers in the further technological development and commercialization, in other words, through a spin-off. In addition, PROs perceive more advantages associated with spin-offs. Table I provides an overview.

\section{Potential strengths of IP-based spin-offs: a public policy perspective}

Policy makers are generally interested in the development of spin-offs from PROS as they are considered to bring along economic growth and create new jobs. Recent data show, for instance, that no less than $44 \%$ of all the life science firms founded in The Netherlands between 1990 and 2002 are spin-offs (Biopartner, 2002). In comparison with corporate spin-offs, however, PRO spin-offs grow considerably slower, a finding that may be explained by the fact that they tend to operate in new areas of highly complex and more radical technologies (see Claryse et al., 2001). In this respect, PRO spin-offs may be of substantial importance to creating and establishing more radical technological breakthroughs and innovations. Other reasons why policy makers are interested in PRO spin-offs are that they may create new fields of entrepreneurial activity in the proximity of a PRO. This, in turn, may contribute to innovativeness, economic vitality and competitiveness of the particular region. So, in fulfilling an intermediary role between PROs and businesses, they may contribute to economic renewal and improve regional employment and development.

Another relevant issue here is that IP-based spin-offs may help in keeping promising entrepreneurs 'at home', who might else go abroad when being too much constrained in their ambitions. In addition, over time spin-offs may become exporters of knowledge, products and services. A final issue here is that (tacit) expertise held by employees of such firms, may diffuse more widely once these people leave and join other organizations. A well-documented example is that of Fairchild Semiconductors, a Silicon Valley-based spin-off firm that has been a breeding place for many other, very successful firms in that area (see Rothwell, 1983). On the downside, a potential risk of (over)stimulating IP-based spin-offs is that it may negatively affect the focus on knowledge creation

Table I

Perceived reasons to promote PRO spin-off projects

\begin{tabular}{ll}
\hline $\begin{array}{l}\text { Contribute to } \\
\text { regional development }\end{array}$ & $\begin{array}{l}\text { Jobs (Creation of employment, particularly high tech jobs; Keep graduates in region) } \\
\text { Better industrial structure (New types of industry; Development of knowledge based companies; New } \\
\text { products open new markets outside region; A lot of research capacity: spin-off potential) }\end{array}$ \\
$\begin{array}{l}\text { Transfer of technology } \\
\text { Improve technology }\end{array}$ & $\begin{array}{l}\text { Stimulate collaboration between PROs and industry } \\
\text { transfer to industry }\end{array}$ \\
& $\begin{array}{l}\text { Get closer to industry and market } \\
\text { Structured approach to enterprise development }\end{array}$ \\
& Possibility of clustering, make a focus \\
Better performance & Education (Helps to develop student curriculum; Getting a better education; Pro-active programme) \\
towards students & $\begin{array}{l}\text { Professional perspective (Reduce graduate unemployment; Counterpart for multinationals) } \\
\text { Improve PRO culture } \\
\text { and image }\end{array}$ \\
& $\begin{array}{l}\text { Culture (Alternative career option researchers; Make profit from research; Industrial research labs 'realise } \\
\text { innovation') }\end{array}$ \\
& Image (Makes institutes more acceptable political and social; Attract better students/staff; Increase quality \\
& of institute; Gaining funds for better research)
\end{tabular}

Source: UNISPIN (1999), reprinted in Van der Sijde and van Tilburg (2000). 
at PROs, by systematically undervaluing fundamental research in comparison with applied research.

\section{Some empirical facts on the Netherlands and the US}

When comparing available data on both IPRs and spin-offs for the Netherlands and for the US, we can observe one clear trend (see also Table II): all figures are higher for the US, not only in absolute sense but also in relative sense. The most striking difference is that of licensing income per PRO, which is tenfold higher: on average, university TTOs in the US annually generate 7.7 million Euro, whereas their Dutch counterparts on average receive 0.8 million Euro. For other figures, such as the number of licenses per PRO and the number of spin-offs, the differences are closer to a factor of two. As a general conclusion we can say that PROs in the Netherlands have less experience in patenting and stimulating spin-offs than their US counterparts. And most certainly, they are far less experienced than the US front-runners. For this reason, we expect that the Netherlands will to be able to learn a lot from US experiences.

\section{Conceptual framework and methods of data collection}

Now that we have defined and described IP-based spin-offs in more general terms, we will further consider the main topic of this paper, namely the role of different institutional factors in conditioning the effectiveness of IP-based spin-offs as a mechanism for technology transfer. At first glance, and when reviewing the literature, we can think of a wide array of institutional factors that may influence their effectiveness. For example, as mentioned in the literature, PRO policy regarding technology transfer is considered to play an important role (Argyres and Liebeskind, 1998). This role affects whether a PRO will make use of IPRs, whether spin-offs are established and in how far they are supported (Di Gregorio and Shane, 2003; Markman, et al., 2004; Kenney and Goe, 2004). This policy, in turn, is strongly embedded in a national institutional environment (Graham and Mowery, 2003; OECD, 2003), as well as in a sectoral environment (Nerkar and Shane, 2003). In other words, national laws and policy as well as sectoral factors may influence the effectiveness of IP-based spin-offs (Jaffe, 2000; Cohen and Merrill, 2003; OECD, 2003). In addition, firm internal factors may play a substantial role as well (Wintjes, 2002; Casper and Whitley, 2004). In fact, over the past decade the literature has expanded greatly and has pointed to the role of different kinds of factors.

In order to better understand the role and relevance of this variety of factors, and how they interrelate, we propose two steps. A first step entails to distinguish factors that mostly affect the potential to establish an IP-based spin-off, and once established, from those factors that mostly affect its subsequent chances of success. As we will show in the following sections, these are two different issues and should therefore be kept analytically separate. A second step is to make use of a conceptual framework, developed in earlier research, which differentiates among four institutional layers of a national system of

Table II

Data on patenting and spin-offs in the US and in The Netherlands in the year 2000 or 2001

\begin{tabular}{lll}
\hline & Netherlands & US \\
\hline Total number of patents granted, nationwide & 64 (universities) & 3617 (universities) \\
& 103 (other PROs) & 1486 (other PROs) \\
Average number of licenses negotiated per TTO & 14.7 (same for universities and other PROs) & 24.1 (universities only) \\
Average income from IP per TTO & 0.76 million Euro (all PROs) & 7.7 million Euro (universities only) \\
Average number of spin-offs & 1.07 (universities) & 2.0 (universities) \\
& 0.67 (other PROs) & \\
\hline
\end{tabular}

Source: OECD (2003). Data from the Netherlands based on a sample including 23 Dutch universities and 13 other PROs. Data on the US includes 168 US universities and 10 other PROs. What are referred to as start-ups in the OECD study fall under the definition of spin-offs in this paper. 
innovation (Van der Steen, 1999, 2003). These various institutional layers of a national innovation system form the selection environment PROs and IP-based spin-offs (Nelson, 2001). The basic idea of the model is that these different institutional layers are structured in a hierarchical order that brings the benefit of being able to systematically rearrange and analyze the different institutional factors that influence the creation and success of IP-based spin-offs. Figure 1 demonstrates that the conceptual model consists of four relevant institutional layers that each has an effect on the potential to establish an IP-based spin-off and/or on its subsequent success chances. In the following sections we discuss each layer in more detail.

Following this framework we propose to distinguish between four institutional layers. The first institutional layer refers to the national economy. The second layer consists of institutions at the sectoral level, including sectoral differences in knowledge transfer and appropriation strategies and patenting behavior. The third level comprises university policies concerning IP-based spin-offs, including university patenting policy and technology transfer strategy, arrangements and activities. The fourth level is the micro-level, focusing on the management of the IP-based spin-off.

\section{Methods of data collection}

Following the logic of this framework we have combined three data collection methods. First, we have analyzed the available literature. The second method entailed a survey on university patenting in the Netherlands (Arundel et al., 2003). This survey, co-leaded by the authors of this article, was conducted as part of an OECD study group of 15 countries on university patenting and university spin-offs. Thirdly, we have conducted a number of interviews. With regard to universities we have interviewed eight research universities, four of which were based in The Netherlands and four in the United States. At the universities we have interviewed the managing director of the Technology Transfer Office (TTO), faculty members and research directors. In addition, we have analyzed the vision and policy of the university board based on annual reports and formal policy documents. With regard to firms we have interviewed six spin-off firms, four of which were based in the Netherlands and two in the US. These firms were established in the life sciences (including biotechnology, pharmaceuticals, medical technology and agro-food) and information- and telecommunications technology (ICT) sectors. For the interested reader, we have added four selected cases as an appendix.

\section{First layer: national law and policy}

The first institutional layer in our conceptual model (see Figure 1) discusses national law and policy. In this section we discuss two key characteristics of this layer: national patent law and

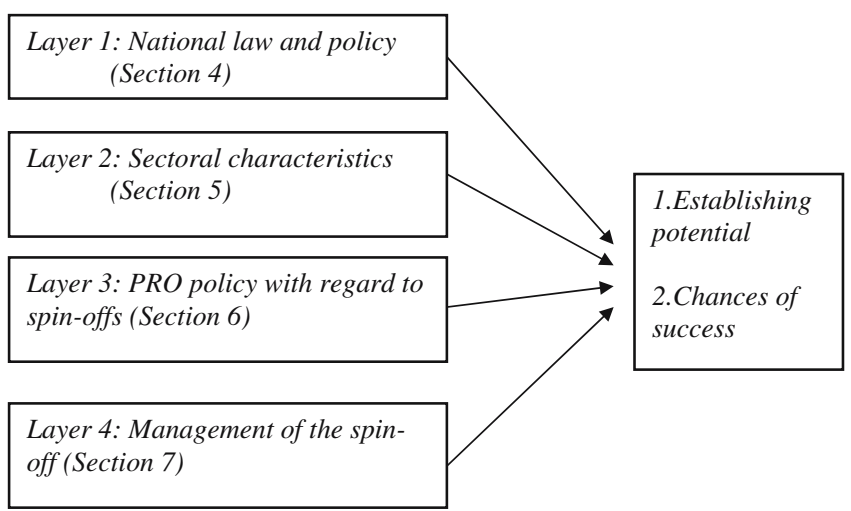

Figure 1. Conceptual model of different institutional layers that affect the establishment and chances of success of IP-based spin-offs (adopted from van der Steen, 1999). 
policy and national spin-off policy. As we will argue, these two elements mostly influence the potential to establish IP-based spin-offs.

\section{Establishing spin-offs: patent law and policy}

In order to structure our insights on the role of patent law and policy in establishing IP-based spin-offs, we distinguish between the more general impact of the national system of laws including the 'Grace Period' and the more specific impact of the Bayh-Dole Act. Compared to the Netherlands, the US system of patent laws is in principle more beneficial for PRO patenting and the potential to establish IP-based spin-offs. This has two reasons. First, the US system favors in principle the right of patent owners (Merges, 1997; Lanjouw and Lerner, 2001). ${ }^{3}$ As a logical consequence, a US PRO that wants to patent its invention and commercialize it in the form of an IP-based spin-off, has legally a stronger position than a PRO in the Netherlands. This increases the chance that an IP-based spin-off will be established.

Second, the US patent law applies to a broader set of patentable inventions (Cohen and Merrill, 2003; Ziedonis, 2003). As a logical consequence, a larger domain of PRO inventions is receptive for patent application and in principle to be commercialized in the form of an IP-based spin-off. In fact, the US legal extension of patentable inventions of the recent years concerned in particular new technological fields such as research tools, life forms and genetic inventions in biotechnology. It is precisely in these technological fields that PROs have a strong patent position and tend to establish IP-based spin-offs (Jaffe, 2000; Mowery et al., 2001; Wintjes et al., 2002; OECD, 2003). This combination of reasons creates a higher potential number of inventions to patent and increases possibilities to establish IP-based spin-offs in the United States, when compared to the Netherlands.

Moreover, the US have another element in their patent laws that has a more specific impact on patenting behaviour of PROs and the potential to establish IP-based spin-offs, known as the 'Grace Period'. The Grace Period allows a limited period after publication of an invention, for instance in a scientific journal, during which a patent can still be applied for. This limited period of respite has in principle a positive impact on the creation of IP-based spin-offs because it enables small-scale inventors and researchers who are usually the ones involved with spin-off creation. This brings two important benefits. First, it allows individual researchers to publish without blocking the road to patent application. Herewith, the Grace Period overcomes a potential conflict of interests between on the one hand, the researcher's obligations and interests to publish his/her scientific invention in journals and present at conferences and, on the other hand, the commercialization of the invention and the establishment of a IP-based spin-off (Nelson, 2001). A second benefit is that the Grace Period allows universities or IP-based spin-offs to obtain support or seek publicity for their innovation before they decide to submit an application. As a consequence, the Grace Period diminishes the risks involved with patenting and licensing. In contrast, the Netherlands do not have a Grace Period. Recent discussions at the EU-level to establish a Grace Period led to the conclusion that, from a legal perspective, the European 'first-to-file' system conflicts with a Grace Period type of arrangement (Galama, 2000; EC, 2002), so that it should not be installed.

\section{The Bayh-Dole Act}

The Bayh-Dole Act (1980) has in particular encouraged non-profit research organizations and small businesses to patent inventions. The BayhDole Act has helped to create incentives for research organizations that perform governmentfunded research to protect, manage and exploit intellectual property and create IP-based spin-offs (Henderson et al., 1998). The specific elements of the Bayh-Dole Act, specific in comparison with the institutional arrangements in the Netherlands, will be further discussed below. The Bayh-Dole Act (1980), in particular the '35 United States Code' (USC) 202 of the Act, encourages non-profit research organizations and small businesses to acquire title to inventions developed with public support. Herewith the Bayh-Dole Act provided for institutional ownership for PROs and IP-based spin-offs. In addition, universities may not assign their ownership of inventions to third parties, except to the Technology Transfer office (TTO). This entails an obligation of the PRO to be engaged in 
the management of their intellectual property and in spin-off creation.

In the Netherlands, the Dutch Patent Act grants in principle research universities title for ownership unless agreed otherwise by contract. Although PROs that perform government-funded research are allowed to patent and license inventions, PROs are independent in deciding on their own specific patent and license ownership policy. Therefore, patent and license practice varies greatly from institute to institute in the Netherlands (Arundel et al., 2003).

In the US, disclosure and exploitation of the university patent are essential since the Bayh-Dole Act. According to the Act, the PRO is obliged to have written agreements with its faculty and technical staff requiring disclosure and assignment of inventions. ${ }^{4}$ At many US universities this obligation to disclose information has resulted in a more active Technology Transfer Office including a more active stance towards spin-off creation (Nelson, 2001; OECD, 2003). In contrast with the United States, PROs and university researchers in the Netherlands have no legal or regulatory obligation to disclose and exploit intellectual property. There is no legal or funding requirement from the national government for PROs to report to the funding agencies or rules for disclosure of inventions or IP activity of researchers to their research institute. Sometimes it is arranged for in specific university regulations (OECD, 2003). Therefore, the chance that PROs have a more active stance towards the establishment of IP-based spin-offs will be higher in the US than in the Netherlands.

The Bayh-Dole Act provides for royalty sharing from patents and licenses as an incentive to encourage researchers and PROs to disclose and exploit inventions. To stimulate disclosure of inventions by researchers, PROs and inventor(s) share revenues received from licensing the invention. According to Nelson (2001), and confirmed by our own interviews, the incomes of university researchers and the funding of their labs have become more sensitive to royalty income and herewith form an incentive to IP-based spin-off creation; some faculty professors earn a good income by holding stock in IP-based spin-offs that draw on their inventions and knowledge. In contrast with the US, in the Netherlands there are no national laws or institutional guidelines for allocating royalties from patents or licenses. Here, rules of royalty sharing depend on the individual PRO patent policy. Sometimes, these policies do not exist and herewith this financial incentive to establish spin-offs is not as common as in the United States (Arundel and Bordoy, 2002).

The Bayh-Dole Act stipulates that in licensing practice, the PRO must give preference to small business firms. i.e. fewer than 500 employees (there is a provision, however, that these firms must have the resources and capability for bringing the invention to practical application.). The current US pro-small business stance follows from the fact that US PROs create by far the largest number of spin-offs (OECD, 2003).

A key characteristic of the research landscape in the Netherlands is that the industry-science relations are often less formal and the ownership of intellectual property of industry-science research is not regulated by law (OECD, 2003). Therefore, scientific inventions of privately sponsored research are often shared between the firm and the PRO. In many cases it is unclear however, whether this reflects actual joint ownership of a patented invention or a contract that requires the research university to license a patent on an exclusive basis to the sponsoring firm (Arundel and Bordoy, 2002). Clearly, in the Dutch industry-science environment there is a stronger incentive to transfer (ownership) of patent rights to larger business firms than to create an IP-based spin-off.

\section{Establishing spin-offs: national spin-off policy}

Formally, the US do not have a federal spin-off policy. However, Etzkowitz (2003, p. 48) uses the term 'Public Venture Capital', to include a substantive set of various government programs both at the federal and local level that provide funds to innovative spin-off firms to help them realize economic gains from scientific and technological advances. In the 1990s, the Office of Science and Technology (OSTP) has formulated technology transfer and research cooperation, particularly involving small and medium sized companies, as a 'critical building block' of technology policy (Bromley, 2004). So, in practice the federal government supports a strong spin-off policy, based on the conviction that they stimulate economic 
growth. Moreover, technology transfer is listed prominently on the agenda of the different states. The state government programs to assist innovative spin-offs are substantive, according to Etzkowitz (2003) up to 3.5 billion US dollars. The underlying idea here is that universities are important drivers for economic development and that applied research should be strongly stimulated. Usually, it concerns economic development within the state borders. Many state programs offer different forms of entrepreneurial assistance, including small grants to develop projects that can become eligible for larger federal grants. State programs also support entrepreneurs to overcome funding gaps in federal programs. The programs may also include tax reductions schemes, financial incentives to stimulate cooperation between universities and companies. Sometimes state governments and municipalities provide in different ways for the right service infrastructure and entrepreneurial climate for spin-offs, for instance in the form of incubators and technical assistance. An example of an active state policy can be found in the State of Utah (see for instance Utah Technology Alliance, 2001).

In the Netherlands, spin-off policy is part of the innovation policy of the Ministry of Economic Affairs. Since the 1990s several subsidy schemes exist, ${ }^{5}$ however, it is only since recently that the new innovative spin-off firms are considered as top priority for economic development (Ministry of Economic Affairs, 2003a). In this respect, the Netherlands try to stimulate spin-off creation by creating a 'breeding' place for IP-based spin-offs through pre-seed facilities, incubator parks and improving the entrepreneurial culture. These measures should tackle three major barriers to spin-off creation: the absence of risk capital (specifically early stage funding), a weak entrepreneurial culture, and a lack of entrepreneurial skills (Ministry of Economic Affairs, 2003b).

\section{In conclusion}

With regard to the role of national laws and policy, as the first institutional layer in Figure 1, we can conclude that the US system of patent laws and policy (including the Grace Period) favors PRO patenting and the potential to establish IPbased spin-offs, compared to The Netherlands. In addition, the Bayh-Dole Act has provided a clear incentive for university patenting and has increased the potential for creating IP-based spinoffs in the US. In particular, its mandatory disclosure and reporting, its rules for royalty sharing and its focus on small businesses. Moreover, spin-offs are much more prominently on the US agenda than in the Netherlands. As a consequence, the US government spends a much larger budget, also relatively speaking, to support spinoff creation and has more experience with spin-off policy. This positive governmental stance towards spin-offs may provide an additional incentive for PROs in the US to establish IP-based spin-offs.

\section{Second layer: sectoral characteristics}

The role of national institutions notwithstanding, new knowledge creation and its effective transfer are also importantly shaped by sectoral institutions (Pavitt, 1984; Malerba and Breschi, 1997). This section discusses the role of such sectoral institutions, the second layer in our conceptual model. In developing our understanding of the role of this sectoral layer, we first discuss the role of the sectoral knowledge base that conditions the extent in which it is attractive to establish an IPbased spin-off. Once established, our findings indicate that it is the presence of regional clusters that shape the subsequent chances of success.

\section{Establishing spin-offs: the role of the sectoral knowledge base}

Empirical evidence on the importance of sectoral institutions can be found in for instance Arora et al. (2002). These empirical studies indicate that there exist strong sectoral differences in knowledge transfer, appropriation strategy and IPR behaviour. Especially in knowledge intensive industries, the most determining factor of such sectoral differences is formed by the characteristics of the sectoral knowledge base (Malerba and Breschi, 1997; Coriat and Weinstein, 2003). The specific properties of the sectoral knowledge base have a profound effect on knowledge creation, its diffusion, possibilities for protection, and hence for the potential to establish IP-based spin-offs. It is especially in the case of a specialized, monodisci- 
plinary knowledge base in combination with codified and tacit knowledge as key-outcomes of the search process, that IP-based spin-offs form an attractive vehicle for transferring such knowledge. Let us further clarify.

Monodisciplinary knowledge makes that an innovation relies on an in-depth understanding of a (relatively) narrow field of expertise (Teece, 1986). In this case, the source of innovation typically lies within such firms, which creates the need to protect against spill-overs and imitation. As argued, this may not be so difficult when knowledge is tacit with its limited potential for spill-overs and absorption by others. However, in the case of science-based knowledge, as developed at universities and PROs, knowledge is highly codified and the occurrence of spill-over may increase, as codified knowledge diffuses more easily and more widely (Nooteboom, 2000). In this case, the use of IPR becomes an effective mean to protect against spill-overs. Under these conditions of properties of sectoral knowledge, not surprisingly, firms are not inclined towards rapid disclosure. Proprietary knowledge can only be disclosed after being assigned a patent. At the same time, knowledge with regard to the search process itself remains highly tacit, being embodied in people and research teams. So, under these conditions IP-based spin-offs form an attractive vehicle for technology transfer of both the codified and tacit elements of the knowledge base. This combination of codified and tacit knowledge is an important point. If it is only the codified knowledge that needs to be transferred, licences form a more efficient alternative. If it is mainly tacit knowledge that needs to be transferred, more efficient means of technology transfer are formed by mobility of researchers, co-location of research facilities of firms and PROs, 'centres of excellence' and so on. Such mechanisms enable a close interaction between the involved people, which is very important for the transfer of tacit knowledge (Malerba and Breschi, 1997; Nooteboom, 2000). So, IP-based spin-offs can best be used in sectors in which predominantly monodisciplinary knowledge is developed, containing codified and tacit elements that both need to be transferred in view of commercial application.

Given this, it is interesting to see that IP-based spin-offs form one of the key-vehicles for technology transfer in the biotechnology industry
(McKelvey and Orsenigo, 2004; Pisano, 2002; Gilsing and Nooteboom, 2006). In this industry, new technological knowledge is firmly rooted in a specific kind of scientific discipline such as molecular biology, genomics, combinatorial chemistry or others, entailing important codified and tacit elements (Enzing et al., 2003). Given its strong scientific content, this knowledge is of a more mono-disciplinary nature and generally highly codified through academic publications. In addition, an important element of the search process is tacit and consists up of skills and routines regarding the process of scientific research itself. These tacit elements are also critical to transfer given the importance for constantly searching for new technological knowledge in the biotechnology industry, and to build up sufficient absorptive capacity (Cohen and Levinthal, 1990).

In contrast are our findings on the ICT-sector. Despite much of the recent attention for software patents, none of the interviewed PROs expected that IPRs would have relevance to them on the short to medium term. These findings were confirmed by the spin-offs that we have interviewed in the ICT-sector. Also these firms were convinced that software patents would have limited value to them. The explanation for this may rest in the more multidisciplinary and predominantly tacit knowledge base of ICT. Moreover, in this sector new technological knowledge does generally not, when in an explorative phase, require an immediate protection through patents. In general, software patents are more relevant for commercial software that is closer to commercialization (Coriat and Weinstein, 2003). As a consequence, nonIPR types of protection were found to play a much larger role, such as secrecy and lead-time.

In sum, we see that the properties of the sectoral knowledge base play a role in the potential to establish IP-based spin-offs. This mechanism for knowledge transfer is best to be used in sectors in which predominantly monodisciplinary knowledge is developed, containing codified and tacit elements that both need to be transferred in view of commercial application.

\section{Chances of success: the role of regional clusters}

In line with the fact that many PROs perceive regional aspects as relevant (see also Section 6), we 
will further discuss the importance of regional clusters. In the literature on clusters, it has been often indicated that regional factors such as the availability of state-of-the-art knowledge, experience, capital, talent and housing support the development of regional clusters. Such clusters are formed by geographical concentrations of interrelated enterprises and institutes, and may show a good performance in terms of productivity and innovation (Porter, 1990, 1998). In this respect, such dynamic, regional clusters may provide a good breeding place for start-ups and for IP-based spin-offs in particular (Jaffe et al., 1993; Mansfield and Lee, 1996; Mowery and Ziedonis, 2001). Proximity and regional embeddeness in a network of public and private collaborations is an important factor for IP-based spin-offs in biotechnology (Audretsch and Stephan, 1996; Oliver, 2004, Zucker et al., 1998).

All our interviewees greatly underlined the role of clusters, and in particular the importance of geographical proximity. Especially during the first phase of the spin-off, housing at the institute or within distance of only a few miles, is considered to be very important. This is confirmed by data from the Association of University Technology Managers, reporting that $79 \%$ of the 364 university spin-offs in 1998 were founded in the state in which the licensing institution is located (AUTM, 1998). So, geographical proximity in the relation between clusters and IP-based spin-offs is crucial and seems to work two ways. On the one hand, the presence of a knowledge-generating engine like a PRO often forms an essential part of a cluster. In this context, IP-based spin-offs are of particular value as they can play a pivotal role in transferring knowledge developed at public research organizations to firms in the cluster that can further capitalise upon it. On the other hand, IP-based spin-offs also benefit largely from geographical closeness within the cluster. The exchange of tacit knowledge with the PRO as much as with firms, informal contacts with former colleagues, possibilities to use laboratory equipment and options to attract new talent, all benefit from geographical proximity (Dahl and Pedersen, 2003).

Our interviewees indicated that another important cluster factor is formed by the availability of start-up capital. This is in line with recent literature claiming that university funding and/or (pre) seed capital is a prerequisite to overcome the period between the establishment of the firm and its first large capital investments (Matkin, 2001). Moreover, Di Gregorio and Shane (2003) mention the importance of the university willingness to make equity investments in start-ups and to keep a low inventor's share of royalties in the incubation period. In the Netherlands, a sizeable proportion $(62 \%)$ of the Dutch spin-offs indicated that attracting sufficient start-up capital forms an important barrier (Ministry of Economic Affairs, 2003a). The value of the intellectual property at this stage of patent life is still uncertain and therefore relatively small (Sherry and Teece, 2004), making it difficult to attract venture capital.

\section{In conclusion}

With regard to the role of sectoral institutions, as the second institutional layer in Figure 1, we can conclude as follows. In establishing IP-based spinoffs it is more the characteristics of the sectoral knowledge base that counts: mono-disciplinary and codified knowledge as outcome of the search process, in combination with more tacit knowledge on the search process itself. With regard to the subsequent chances of success, our findings indicate the role of regional clusters that stimulates the creation of IP-based spin-offs. Proximity of a PRO, venture capitalists, and possibly technical facilities and incubation parks form key-ingredients of such a cluster. This geographical proximity is important in leveraging the potential of IP-based spin-offs, in view of tacit knowledge exchange and other proximity-related benefits.

\section{Third layer: PRO policy with regard to spin-offs}

This section discusses the third layer in our conceptual model (see Figure 1 again) that concerns PRO policy with regard to technology transfer and spin-offs in particular. In order to structure our insights on the role of PRO policy, we distinguish between two types of factors. We first discuss factors that especially shape the degree, in which IP-based spin-offs are established, namely PRO policy. As a next step, we discuss those factors that entail how this PRO policy is implemented in terms of its organizational set-up, type of support 
services and level of formalization. This combination of factors mostly shapes their chances of success, once established.

\section{Establishing spin-offs: PRO Policy}

The technology transfer policy of PROs influences the possibilities to establish IP-based spin-offs. Based on our interviews, we have observed similarities among US universities in their approach of technology transfer and the establishment of IPbased spin-offs. From a more historical perspective, many US universities have always been more involved in technology transfer than universities in the Netherlands. Even before the Bayh-Dole Act, many PROs had departments with a strong focus on applied science that were in close interaction with industry (Mowery et al., 2004).

Nowadays, most PROs in the US have adopted policies for encouraging entrepreneurship and spin-offs (Etzkowitz, 2002; Goldfarb and Hendrekson, 2003; Wright et al., 2004). Most research professors are part-time involved in business consulting, often as a research director, such as at UCLA and Harvard (Nelson, 2001). Almost all US PROs have a technology transfer office and are actively pursuing technology transfer policy through patenting, licensing and/or the creation of IP-based spin-offs. This active involvement with technology transfer increases the chance of establishment of IP-based spin-offs.

Surprisingly, many Dutch PROs do not have some kind of policy in place to stimulate the establishment of IP-based spin-offs. Although national policymakers are aware of the benefits to stimulate the establishment of spin-offs (see again Table 1 in Section 2) and most PROs do have Technology Transfer Offices (TTOs), Wintjes et al. (2002) recently observed that many universities do not yet recognize the benefits neither of a technology transfer policy nor of a policy for encouraging (IP-based) spin-offs. This is supported by most of our interviewees in the Netherlands. Despite the fact, as we observed in our interviews, that at most Dutch TTOs there is generally a strong commitment to support spin-offs, this stands in sharp contrast with ideas of the general university board or faculty policies. An explanation for this observation may be that universities and PROs are not single, consistently acting entities. Instead, they are made up of a number of smaller entities such as an university board, one or more technology transfer offices (TTOs), various faculties consisting of different departments and numerous chairs, all of which have different responsibilities, goals and interests (Etzkowitz, 2003; Kenney and Goe, 2004). Without the pressure from a federal or national framework such as the Bayh-Dole Act it becomes difficult in these circumstances to develop an effective technology transfer policy. As a consequence, this lack of general interest and the absence of a consistent technology transfer policy definitely hinders the establishment of IP-based spin-offs in the Netherlands (Table III).

Apart from the similarities in technology transfer and spin-off policies among US-based PROs, they also reveal important differences. The historical context, the eminence of the PRO, its culture, regulations in general, all influence the interpretation and implementation of technology transfer in practice (Feldman and Decroches, 2003; Kenney and Goe, 2004; Mowery et al., 2004). Based on our interviews, we discuss three aspects of technology transfer policies and how these may differ across PROs as well as between the US and the Netherlands: royalty sharing, equity investments (capital needs) and the role of incubators.

First, university policy with regard to sharing royalty rates between the inventors and the university are important for the establishment of IPbased spin-offs. Clear rules for royalty sharing, as provided by the Bahy-Dole Act (see also Section 4), are important to avoid a conflict of interests. In addition, the literature suggests that higher paysharing rates, as a percentage incentive payment from licensing revenues given to either a scientist or to its department, may result in a decrease of the number of university spin-offs. Other studies seem to confirm this, namely that a (certain) share of royalties obtained by the inventor increases the establishment and success of IP-based spin-offs (Hsu and Bernstein, 1997; Matkin, 2001). To sum up, clear university rules and a low inventor's share of royalties are both important conditions for the establishment and success of IP-based spin-offs. 
Table III

Dutch PROs categories, their identified spin-offs, and patents

\begin{tabular}{|c|c|c|c|c|}
\hline Category & $\begin{array}{l}\text { Academic } \\
\text { staff }(2001)\end{array}$ & $\begin{array}{l}\text { Number of } \\
\text { institutes }\end{array}$ & $\begin{array}{l}\text { Patent } \\
\text { applications 1990-1999 }\end{array}$ & $\begin{array}{l}\text { Identified } \\
\text { spin-offs (2001) }\end{array}$ \\
\hline Universities of which: & & 13 & 224 & 499 \\
\hline Technische Universiteit Delft (TUD) & [2332] & & 90 & 57 \\
\hline Rijksuniversiteit Groningen (RUG) & 1470 & & 26 & 42 \\
\hline Rijksuniversiteit Leiden (RUL) & 1610 & & 24 & 12 \\
\hline Universiteit Utrecht (UU) & 2108 & & 19 & 4 \\
\hline Universiteit Twente (UT) & 771 & & 18 & 226 \\
\hline Technische Universiteit Eindhoven (TUE) & 743 & & 17 & 40 \\
\hline Universiteit van Amsterdam (UvA) & 1708 & & 10 & 19 \\
\hline Katholieke Universiteit Nijmegen (KUN) & 1483 & & 8 & 30 \\
\hline Vrije Universiteit Amsterdam (VU) & 1269 & & 4 & - \\
\hline Universiteit Maastricht (UM) & 783 & & 3 & 39 \\
\hline Erasmus Universiteit Rotterdam (EUR) & 847 & & 3 & 20 \\
\hline Wageningen Universiteit (WU) & 839 & & 2 & 10 \\
\hline Katholieke Universiteit Brabant (UvT, formerly KUB) & 274 & & 0 & - \\
\hline Academic hospitals & & 8 & Not available & 0 \\
\hline Large technological institutes & & 5 & Not available & 11 \\
\hline $\begin{array}{l}\text { Institutes of The Netherlands Organisation } \\
\text { for Applied Scientific Research (TNO) }\end{array}$ & & 20 & Not available & 21 \\
\hline Agricultural Research Service (DLO) & & 8 & Not available & 3 \\
\hline Netherlands Organization for Scientific Research (NWO) & & 9 & Not available & 11 \\
\hline Royal Netherlands Academy of Arts and Sciences (KNAW) & & 21 & Not available & 0 \\
\hline Top technological institutes & & 4 & Not available & 0 \\
\hline Institutes for higher professional education & & 36 & Not available & 1 \\
\hline Totals & & 124 & & 546 \\
\hline
\end{tabular}

Data on the number of institutes and identified spin-offs is based on Senter (2001). Source of patent applications is based on AWT (2001). Data on academic staff is based on the report "Digitaal Ontsloten Cijfers-DOC (2001)" by the Associations of Universities in The Netherlands (VSNU). Data on academic staff concerning TU Delft, which is lacking in the other sources, is based on the report 'Personeelomvang TU Delft in fte 1990-2002' published by that university.

Second, PRO policy with regard to equity investments in IP-based spin-offs plays an important role. The willingness of the university to take an equity stake in its spin-off affects the establishment and the success of an IP-based spin-off. Spin-offs typically lack cash, which limits its possibilities to cover patent costs, up-front license fees, costs of research facilities and marketing activities. Di Gregorio and Shane (2003) confirm that equity investments of the university in their own spin-off are more important in early stages of a spin-off creation than the availability of formal venture capital. This is confirmed by our interviews at Yale University and the University of California, indicating that the active pursuit of an equity programme stimulates the establishment of spin-offs. These findings are in contrast with policy in the Netherlands, with its main focus on providing venture capital in order to stimulate the creation of university spin It concerns in particular new technological fields such as research tools, life forms and genetic inventions in biotechnology, software and business methods in the field of ICT off (see also Section 4). This type of policy negates the notion, as advanced in the literature that the role and the type of risk capital needed for an IPbased spin-off changes over time (Bromley, 2004). So called 'business angels', with an average net worth of less than US\$ 300,000 , and universities themselves through equity investments in their own spin-offs, are especially important in the early stages of development of an IP-based spin-off (Di Gregorio and Shane, 2003). In the next phase risk capital is necessary for further growth and typically comes from venture capitalists. In further phases of IP-based spin-off development the role of federal and local government research grants in combination with $\mathrm{R} \& \mathrm{D}$ cooperation with other 
(larger) firms becomes important (Bromley, 2004; Sherry and Teece, 2004). So, governments need to be aware of the full range of risk capital that is needed along the path from initial establishment towards successful growth of an IP-based spin-off. Solely relying on sources of venture capital does clearly not suffice for the establishment of IP-based spin-offs.

A third element of technology transfer policy is the availability of incubator parks for IP-based spin-offs. Such incubator parks allow spin-offs to develop university technology further in close proximity of the scientist inventors. In an early development stage of a spin-off, the scientific input of the local inventor is very important for the further development of the technology in view of future commercialization (Jensen and Thursby, 2002). Apart from providing access to the university, these incubator parks may reduce costs of development through offering subsidies and offer the possibility of sharing of overhead costs. However, in the literature as well in practice, this positive impact of university-affiliated incubators on the establishment and success of IP-based spinoffs is not uncontested (Phillips, 2002; Di Gregorio and Shane, 2003; Appold, 2004; Markman et al., 2004). In our interviews at Columbia University it was stressed that subsidized incubator parks keep the weak firms alive, consuming the research facilities and potential venture capital from successful ones.

In the Netherlands however, our interviews with Dutch spin-offs indicated that access to such facilities, through a proper arrangement with their PRO was perceived as an important key success factor. In order to prevent a potential risk of conflict of interests, some Dutch spin-offs mentioned that they prefer to pay a fair price to the institute for using its facilities such as laboratory access, secretarial support or housing.

In contrast to the Netherlands, national legislation in the US generally prohibits access to PRO facilities by commercial firms. This may depend, among other things, on the status of the university (public or private). As a result, spin-offs have to foresee in their own needs and obviously only those with sufficient funds may be able to do that. These observations more pertain to the life sciences sector as, in general, many spin-offs in the ICT sector do not need the kind of facilities as described above. Generally, an office and a set of computers is all it takes to start off (although we recognize that in some domains of the ICT sector costly laboratory facilities are required as well).

So, in the US we found that there is a much 'thicker wall' between institutes and firms. For this reason, long-term support is more limited such as access to facilities such as laboratories. Most universities will not allow such access, and state universities are not even allowed to do so because of their public status.

\section{Chances of success: implementation of PRO policy}

Now that we have discussed policy strategy and its contents, we further focus on how this policy 'reaches' IP-based spin-offs, being the 'target group'. Instrumental in this respect, and basically affecting the chances of success, are its organizational set-up, the level and type of support, the type of contractual arrangements and the degree of formal distance between PRO and spin-off.

Apart from the contents of PRO policy, there are also some relevant organizational considerations. Various organizational models exist for both technology transfer and spin-off support at universities. Most often, both activities were performed in one single office, most often referred to as Technology Transfer Office (TTO). Whereas most TTOs deal with all aspects of technology transfer, we have also come across cases where IPR activities were entirely separated from spin-off support activities. On the other hand, some universities have outsourced all technology transfer activities to a specialized third party. An example is ARTI of Indiana University. This type of organizational set-up increases the flexibility of the technology transfer activities for instance to apply (university) funds for certain spin-offs activities (Matkin, 2001).

In the Netherlands, most Dutch universities have the TTO office in-house. Compared to the United States, Dutch TTOs are generally small and often employ no more than 1 or $2 \mathrm{fte}$ 's. As a consequence, people have to be generalists rather than specialists and consequently they have to rely on external expertise as well. In contrast, TTOs at the large US universities that we visited often employ as many as $10-25 \mathrm{fte}$ 's. In the US, most TTO staff used to be administrators with a 
generalist background like in the Netherlands today. However, we were informed that many TTOs are turning into professional specialized teams with top experts on patent application, licensing negotiations, successful business people and spinoff entrepreneurs. An example is the TTO of UCLA.

Another observation is that that many TTOs in the United States function more and more as professional learning organizations with professional teams of highly motivated people. In contrast, in the Netherlands the rather inflexible nature of university policy tends to inhibit such professionalisation trends of TTOs. For instance, the lack of flexibility of salaries of TTO personnel, which is often part of general university policy, can limit possibilities to attract star business people or legal personnel. This ongoing professionalizing of TTOs in the US will positively enhance chances of success if IP-based spin-offs (OECD, 2003). The communication and marketing activities of TTO personnel are important for the creation of university spin-offs (Markman et al., 2004). It involves in particular TTO activities with regard to inventions at an embryonic stage of development, which are often further developed in IP-based spin-offs.

The downside of expanding the commercialization of transfer technology offices is that some are behaving too aggressively. Our interviews confirmed the observation of Nelson (2001, p. 17) that some firms in the US are becoming increasingly dissatisfied with the way universities are claiming and trying to profit from intellectual property. In the literature, and confirmed by our interviews, Columbia University is mentioned several times as an exemplary case.

The level and type of support for IP-based spinoffs differs across PROs, both in the US and the Netherlands. Depending on the presence of strong regional clusters, such support may not be needed at all. In the case of Silicon Valley, home to institutes such as Caltech, Stanford and Berkeley, there is strong interaction among PRO staff, businesses, capital providers and entrepreneurs. In such a setting, spin-offs have a fair chance to make it on their own. Support for them may come from private parties such as specialized venture capital providers or 'business angels'. This diminishes the need for specific support by the PRO, which then often only acts as a licensing agent.
However, in most areas such a regional cluster is less developed, or even absent. In this respect all interviewees agreed that in such a case, an actively supporting role by a PRO will certainly have a positive effect on the success changes of spin-offs, by offering support and facilities to overcome such lack of resources. Types of support that were mentioned during the interviews were: secretarial and other facilitative support, options for housing, access to facilities such as laboratories, libraries and support with finding additional sources of funding and facilities (Matkin, 2001).

The contractual (IP) agreements between PRO and spin-off differ widely. Some PROs transfer the ownership of the IP rights the spin-off. In return, the institute receives a lump sum or, more commonly, a part of the shares ('equity') of the new firm. The advantage for the PRO is that all costs are taken away, including the burden for obtaining and retaining an IPR. Other PROs decide to retain IP ownership and provide a license to the spin-off instead, either on an exclusive or non-exclusive basis. For PROs this brings the advantage that IP rights are not lost, in the case of unforeseen bankruptcy by the spin-off. On the other hand, the consequences in case of a possible liability claim can be tremendous. Often the PROs are not capable to deal financially and legally with large IP law cases.

Another issue here is the level of 'formal distance' between PROs and spin-offs. In line with its informal culture, in the Netherlands this distance is rather short. It is considered common practice for the inventor to be highly involved in the new firm, often through a senior management position and sometimes even as CEO. Instead, in the US, the PRO usually prefers that the inventor makes a choice either for the PRO or for the firm, and not for a combination in order to prevent conflict of interest. It is rather unusual for the inventor/faculty member to join the spin-off. Usually this new IP-based is runned by experienced entrepreneurs that are attracted either by the inventor(s), the TTO or a venture capitalist. Most often, the faculty member takes a position as chairman of the Scientific Board of the spin-off, and any possible conflict of interest is well managed. We will further elaborate on this in Section 7. As discussed earlier in Section 4, the US Bayh-Dole Act requires from PROs to offer a compensation scheme for 
inventors, and many of such schemes include rather generous payments to these faculty members. In fact, at one university we talked to, the inventor(s) receive $50 \%$ of the net income up to US $\$ 100,000,40 \%$ between US\$ 100,000 and 200,000 and $30 \%$ of all turnover above US\$ 200,000. By doing an unusually valuable invention (a 'golden egg'), some faculty members became multimillionaires.

\section{In conclusion}

With regard to the role of PRO policy, as the third institutional layer in Figure 1, we can conclude as follows. In contrast to the Netherlands, most PROs in the US have clear technology transfer policies in place and actively pursue patenting and licensing activities, aimed at establishing IP-based spin-offs. Relevant elements of such policy are formed by clear agreements on royalty sharing, the possibility to make equity investments in IP-based spin-offs and the role of incubators. Implementation of this PRO policy through specialized TTO services, clear contractual agreements on IP-protection and the type of staff involvement mostly affect chances of success. The relative absence of such PRO policy in the Netherlands may form one of the key reasons for its comparatively poor performance in establishing IP-based spin-offs and their success chances.

\section{Fourth layer: management of the spin-off}

In this section we discuss the fourth and final layer of our model (see Figure 1 again), which entails the management of the spin-off. We argue that factors at this micro-level especially affect the survival rate and growth opportunities for spinoffs. In other words, this layer deals more with success chances, not so much with establishing a spin-off in he first place. To deal with these managerial issues, we will focus on two aspects: the underlying business model and the presence of entrepreneurial skills and managerial experience.

Chances of success: the underlying business model of the spin-off

Many Dutch spin-offs employ a so-called 'tools' or 'service' business model. For example, the majority of start-ups in the Dutch life science sector, approximately $65-70 \%$, are based on such a business model. This model entails the sale of technology and/research results as well as the provision of services such as consultancy, often in the form of contract research. Although these models have the benefit that they generate income potentially from day one, margins and profits are relatively low and competition is strong(er). This is in contrast to the product-based model, which entails more of a stand-alone strategy by developing a 'blockbuster' product with potentially very high margins but also with considerable costs and risks. Although the combination of IPRs, strong R\&D expertise and secrecy may create first-mover advantages, it generally takes years before the first money is earned, if at all. Therefore, a more viable alternative is emerging that consists of a hybrid model, using elements of both. The general idea is to first develop a strong position around a sophisticated technology platform that can generate cash-flow through licensing fees. These initial revenue streams may then open up possibilities to develop a unique product later on. This model lowers one-sided dependency on larger firms and may create a possibility to cooperate with other start-up firms as well, positively enhancing chances of success.

\section{Chances of success: entrepreneurial skills and management experience}

In the Netherlands it is considered common practice of a scientific inventor to leave the PRO in order to become employed by the new firm or to become CEO of the new firm. Our empirical findings indicate that there two potential drawbacks with such a transfer: (1) the inventor does not necessarily have the right qualities and experience for such a crucial position as CEO, and, (2) the PRO loses a valuable staff member.

In contrast, US spin-offs tend to be run by professional managers instead of former faculty staff. An example is formed by Yale University that has decided to only attract external managers for all its IP-based spin-offs. Also the spin-off Nantero is an example of such an American spinoff where experienced managers are attracted (both cases are described in more detail in the Appendix). 
Based on our interviews we have found two conditions of importance here: (1) the new management needs to be qualified to lead the new firm, and, (2) the risk of conflict of interests should be minimized. This underlines the importance of attracting professional managers from outside. This pre-empts scientists with potentially questionable managerial qualities, to become directly involved and prevents a conflict of interest as he remains at the PRO. This may also explain why most of our US interviewees indicated that IPbased spin-offs without direct staff involvement are seen to have most promising prospects, as mentioned in Section 2. This is also in line with recent EU-findings on remuneration (European Commission, 2002). According to this study, most CEOs of US spin-offs receive a share in the firm but no initial salary, and thus have a strong incentive to make the firm successful. Moreover, US-based spin-offs also tend to be larger in personnel and capital. According to our interviewees, the idea is that this positively influences the presence of the right mix of skills at various levels in the firm.

\section{In conclusion}

With regard to the role of spin-off management, as the fourth institutional layer in Figure 1, we can conclude as follows. Chances of success on the short term seem to benefit most from a service model, whereas on the longer term success chances benefit more from a product-based model. As argued, a hybrid model may be considered as combining best of both worlds. Furthermore, informed by US-experiences, IP-based spin-offs should consider attracting external professionals as CEO and managers instead of the original scientific inventor.

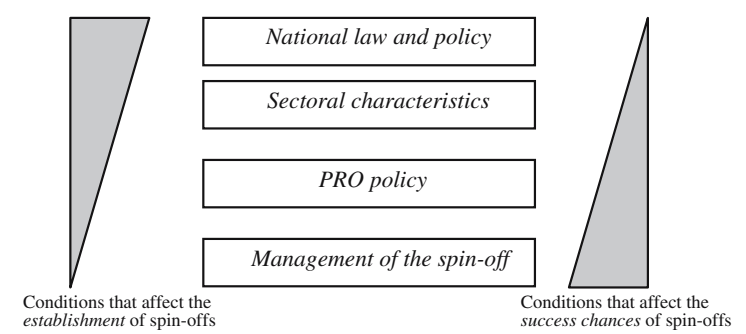

Figure 2. The four institutional layers and their effect on establishing and chances of success of IP-based spin-offs.

\section{Conclusion}

The aim of this paper is to identify which institutional factors determine the possibilities to establish an IP-based spin-off, and once established which institutional factors determine their success chances. To answer this question, we have made use of a conceptual framework that differentiates among four different institutional layers. An indicative comparison between the Netherlands and the United States, as the benchmark in the field of technology transfer, has enabled us to better understand these institutional factors according to their role and relevance. Our empirical findings indicate that all four institutional layers need to be taken into consideration and that these layers differ in their role and level of impact. The higher institutional layers, notably national and sectoral institutions, particularly condition whether such spin-offs are established in the first place. The lower institutional layers, notably PRO policy and spin-off management, more influence their subsequent chances of success. See also Figure 2.

Following the logic of this framework, to increase the number of newly established IP-based spin-offs in the Netherlands is, first of all, a concern for national policy (layer 1). In this respect, national legislation and/or European guidelines may be required to create the necessary incentives for PROs to be actively engaged in technology transfer, including the creation of IP-based spinoffs. Moreover, sectoral characteristics play an important role whether IP-based spin-off are the most effective mechanism for technology transfer or that alternative mechanisms are more preferable (layer 2). Next PRO policy becomes relevant in enhancing the establishment of IP-based spin-offs (layer 3), especially in terms of royalty sharing, equity investments, capital needs and contractual agreements on IP-protection. Once established, it is first of all the management of such a firm that should be 'sufficiently capable' (layer 4). A viable business model, external professionals and no conflict of interest are key issues in this respect. When these conditions are met sufficiently, it becomes sensible to support such a spin-off from the side of a PRO through a variety of means such as the availability of venture capital, housing, access to technical facilities, libraries and so on (layer 3 ). 
And only then cluster-based cooperation with other firms can develop (layer 2), which is critical in two ways. It enhances not only the chances of success of the spin-off firm, but also enables knowledge diffusion from PROs to industry, which again connects with one of the key national policy aims to stimulate technology transfer (layer 1).

In this way, the role and effect of institutional layers can be seen as systemic, in terms of a 'hierarchy of effects'. As far as increasing the number of newly established IP-based spin-offs is concerned, this hierarchy is top-down, starting at the national level (layer 1) and entailing sectoral characteristics (layer 2) and the role of PRO policy (layer 3). As far as chances of success are concerned, this hierarchy of effects is bottom-up, starting at the managerial level (layer 4) and entailing the role of PRO policy (layer 3) and sectoral characterics, most notably the role of regional clusters (layer 2).

We propose that the systemic relations among these layers could form a guiding principle for rearranging policy in the Netherlands, and potentially elsewhere as well, aimed at increasing the effectiveness of IP-based spin-offs as a mechanism for technology transfer. The framework enables to systematically address the right issues in the right order when priority is attached either to increasing the number of spin-offs, to increase their chances of success, or to both at the same time.

Our comparison with the US has provided us with insights in the difference between both countries. Indicated by our figures and confirmed by our interviews, it is fair to say that the US is way ahead in effectively making use of IP-based spin-offs for technology transfer. Our framework has enabled us to relate this difference in performance to differences between both countries in terms of the four institutional layers. In this respect, there is one key difference in particular, at layer 1, that may importantly explain the lagging performance of the Netherlands. Without the 'selective pressure' exerted by a common national framework such as the Bayh-Dole Act in the US, it becomes very difficult to develop a consistent policy for technology transfer and IP-based spinoffs in particular. Some of the differences that we have identified at the lower institutional layers may be seen as a logical consequence of this. At layer 3 this entails, among others, the risk of a conflict of interests among the various involved bodies at a PRO in the Netherlands, such as its among its TTO, university board, faculty directors, individual chairs and so on. Other issues at layer 3 that need to be addressed are unclear rules for royalty sharing, the possibility of equity investments, clearer agreements on IPs and the limited degree of professionalizing of TTOs. At layer 4 this entails more attention for the right business model, attracting external managers with professional managerial skills and no or only very limited direct involvement from former scientific staff.

Informed by our comparison with the US, such adjustments to the national framework (layer 1) may consist of mandatory disclosure and reporting as well as general rules for royalty sharing. Moreover, the introduction of a European Grace Period may also form a good incentive to increase the number of IP-based spin-offs. However, we need to add here that legal incentives and institutional adaptations are not enough. A profound change in the mindset of Dutch researchers, its venture capitalists, its policymakers and the managers of its spin-offs is needed at least as much. Only then we may expect the much sought after growth of the number of IP-based spin-offs and an increase of their success chances, in view of an effective transfer or publicly developed technology to industry.

\section{Acknowledgments}

We thank Dominique Foray for his useful comments on an earlier version of this paper. Of course, the usual disclaimer applies. Finally, we would like to thank the US State Department for partly sponsoring the conducted US interviews of this research with the International Visitor's Grant. Finally, we want to express our gratitude to all organizations and individuals who were willing to share their experiences during the interviews.

\section{Notes}

1. Public Research Organizations (PROs) include universities as well as other (public) research organizations that receive significant public research funds. This definition is based on the OECD (2003). Another, similar term is Public Sector Research 
Establishments (PSREs). In the remainder of this article we will use the term Public Research Organizations that we abbreviate as PRO.

2. Similar trends have been observed in other countries, and have been analysed various national contexts. Nelson (2001), for instance, discusses studied the US situation in which the number of patents granted to universities has increased more than eightfold between 1979 and 2000 .

3. The perception on patent ownership differs profoundly between the United States and the Netherlands. In the US intellectual property system, the entity that can prove that it was the first to develop the invention owns the patent. This is called the 'First-to-Invent' system. In the European so-called 'First-to-File' system, it is the entity that first notifies the invention that is granted the patent. Moreover, the establishment of the Court of Appeals for the Federal Circuit (1982) and its (recent) court decisions clearly strengthened the position of patent owners further. See also Jaffe (2000) and Kortum and Lerner (1999).

4. The university has an obligation to disclose each new invention to the federal funding agency within two months after the inventor discloses it in writing to the university (OECD, 2003). The university must submit periodic reports regarding the utilization of the invention as requested by the funding agency. 5. Several existing programs do offer such early-phase support in Life Sciences such as Biopartner and Genomics. Another example of a university specific program to stimulate the creation of spin-offs is TopSpin programme of the University of Twente.

\section{Appendix: Selected illustrative case studies}

Yale University (New Haven, CT) has a very active TTO that is committed to have successful spin-offs established on the basis of its technology. Its main drivers are a contribution to the local economic development and the creation of a successful biotech cluster in the New Haven area. Yale employs an advanced process that ranges from discovery, disclosure, and opportunity analysis to commercialisation. This process includes various feedback loops as well as includes decision points such as whether to protect the invention or not, and how to commercialize it (licensing to large or small existing firms vis-à-vis the establishment of a spinoff). Main considerations to opt for spin-offs are (1) the chances for success of the technology in question, (2) the degree to which the Yale TTO expertise is necessary, and (3) value creation.

In the Yale model, there are four actors that provide the main inputs for the prospective spinoff: the inventor, the scientists (non-inventors), the university, and the CEO. In return for its input, each will receive $25 \%$ equity in the firm (that is, before the first round of investments).
The inventors' input and that of the scientific team is evident: the invention and its further development are a substantial contribution to the firm. The role of the inventor(s) often includes a position on the scientific board of the start-up firm, among other things. The university's input consists of developing the initial business strategy, applying for and maintaining the intellectual property, recruiting the management and key (science) advisors, and raising money from qualified investors. As a matter of policy, however, the university is not prepared to waive license fees for equity. The CEO, finally, is attracted by the university. His or her role is to further develop business strategy and business plans, recruit additional management, manage the start-up and company formation, negotiate license agreements with the university, and negotiate financing with investors. A typical CEO has a successful start-up track record, is acceptable to investors, understands, accepts \& manages risk, understands science, has realistic expectations and has an entrepreneurial attitude. Although this person initially works at own risk (no salaries paid), the received equity could potentially be very valuable on the longer run. This increases the motivation.

As a result of their pro-active patenting and spin-off activities, Yale has half a dozen to a dozen new spin-offs each year. At this moment, four Yale spin-offs have raised well above US\$ 10 million of public money. Furthermore, Yale-founded spinoffs account for more than $10 \%$ of all biotech investments in New England.

LioniX is a spin-off of the Twente University (The Netherlands). It was founded in January 2001. A year and a half, later it employed 14 persons. LioniX develops and produces integrated optics, innovative components and subsystems for applications in telecommunications, industrial process control and in the life sciences sector. Its appealing products include a lab-on-a-chip for water analysis and an optical chip used for biochemical experiments. Technology developed at the university is a substantial contribution to the creation and operations of this firm. The interesting element is that in this case university knowledge is not protected by patents. Instead, there is an agreement that LioniX has exclusive, early access to university research and inventions. Although these findings are published later 
through the regular channels, the spin-off has a very valuable lead time and can develop products while the competition still has to start to feed their research with the published findings. Apart from this agreement with the TTO, LioniX itself is rapidly building a firm IPR position in its fields.

This spin-off owns several research facilities, and in addition has an agreement that provides access to university-owned facilities. Such access is essential, as the investments for a facility such as a clean room exceeds 20 million Euros. This is an unsurpassable threshold for a start-up company. The access to university facilities is based on a market-based compensation. The biggest challenge LioniX experienced during its establishment phase was to get the necessary funding. Venture capitalists require a solid growth plan plus an experienced management team. With the entirely different culture at PROs, a culture clash is inevitable.

The founders of LioniX believe that there are several ways in which the government could stimulate and support the establishment of spinoffs. Peripheral events such as the administrative burden and housing consume much time and energy that could be better spend on core activities. Support for such activities would be very welcome as part of a university or government programme. Essential, however, is that such support is granted only after the spin-off succeeded in funding its activities. Earlier support interferes with market selection mechanisms, making it undesirable. Also, it is important that within such a program the spin-off must be free to choose where to purchase such support services, as PROs or other institutions are not necessarily the most experienced suppliers.

Nantero is a Boston-based spin-off that was established in 2001and that develops a non-volatile computer memory technology on the basis of a nanotechnology invention at Harvard University. The intended memory chips work on the basis of single-wall carbon nanotubes, which have a wall thickness of 1 atom and a diameter of $0.4-3 \mathrm{~nm}$. The chips are non-volatile, very fast, and have a high density. It may thus replace several types of existing memory technologies such as Flash (often found in portable devices such as digital cameras, PDAs, and mobile phones), DRAM (the main memory of personal computers and laptops) and
SRAM (high-speed memory, used in routers, switches and also for certain purposes in personal computers). Interesting possible uses include the enabling of instant-on computers

The founders of the spin-off, two actual Harvard inventors and an experienced entrepreneur that previously established several start-ups, set up the firm without specific support from Harvard. Although there are many, valuable informal contacts with Harvard (as well as with MIT, in fact), their only formal link is a license agreement.

It is the conviction of Nantero that this new technology would not be adopted by existing market players if they would have been offered a license. Main reasons are that (1) they have already invested in existing technologies, and opt more for incremental improvements, (2) the motivation of all involved to make such a novel technology successful might not be as extreme as that of spin-off employees, whose driver is the high reward in case of success, and (3) they lack the necessary skills (nanotechnology is a rather different field from that of traditional chip engineers). Also, existing firms might take out a license only for defensive reasons.

The business model of this spin-off is a productbased one, not a service model. Nevertheless, it is well imaginable that final production will be outsourced (despite its novelty, the memory chips may be produced with conventional production techniques) or that Nantero will sub-license its product to existing memory producers. Although existing firms tend to opt more for incremental improvements in-house, as discussed above, they are sometimes willing to partner with start-up firms that are pursuing radical improvements. The ideal for the firm would be an IPO, but given the current market situation this is not the right moment. Selling the firm in a later stage is also an option.

Advanced Lightweight Engineering (ALE) is a spin-off of the Delft University of Technology. While studying aerospace engineering, ALEs founder Jan-Jaap Koppert and his professor had been working on specific materials that offer a unique combination of strength and weight. While a patent application was being prepared, it was recognized that possible applications could be much broader than those in the aeronautical sector alone. In particular, it could be used for fuel vessels in cars that run on liquid petrol gas. ALE was 
founded in 1996 and now employs 11 people. One of its strengths is its ability to translate its innovative lightweight technologies for use in other sectors. Apart from fuel vessels for cars, ALE is involved in gas bottles for the home appliances market (for cooking and heating, as used by $60 \%$ of all people worldwide) and structural parts of marine vessels. It also produced a number of satellite antennas for the European Space Agency (ESA). Apart from product design, ALE offers services in the field of testing and research for multinationals like Airbus and Akzo Nobel.

A substantial contribution to the start-up of this firm was a patent application that was transferred from the university to the spin-off. About the early relation with the university, ALEs founder recalls: 'One problem is that the TTO is wearing two hats. On one hand, it aims to facilitate a successful startup, on the other it has an interest in maximising the gains from its intellectual property. Although we did not experience real problems ourselves, such a conflict of interest could hamper good negotiations'.

According to its founder, the real value of spinoffs such as ALE lies in the available tacit knowledge, and the motivation and enthusiasm of people involved. ALEs relation with the university is one in which cross fertilisation prevails, both in the field of knowledge and market developments. Furthermore, the relation with the university offers ALE a valuable recruitment ground, while the university is able to offer opportunities to its students. In ALEs field, access to research facilities (laboratories) is crucially important, as well as access to people and knowledge. In that respect, improvements can be made. However, support by universities for spin-offs should be essentially limited to providing facilities: 'In the case of $A L E$, the search for capital went relatively smooth. Anyway, in my sector, nobody believes in financial subsidies by universities. If a prospective entrepreneur is not able to raise capital by himself, there is something essentially wrong. One should not subsidise such cases'.

\section{References}

Adviesraad voor het Wetenschaps- en Technologiebeleid (AWT), (2001) Handelen met kennis: Universitair octrooibeleid omwille van kennisbenutting [Trade with Knowl- edge: Universities' Patent Policies for Knowledge Utilisation], The Hague.

Appold, S., 2004, 'Research Parks and the Location of Industrial Research Laboratories: An Analysis of the Effectiveness of a Policy Intervention,' Research Policy 33, 225-243.

Argyres, N. and J. Liebeskind, 1998, 'Privatizing the Intellectual Commons: Universities and the Commercialisation of Biotechnology,' Journal of Economic behaviour and Organization 35, 427-454.

Arora, A., M. Ceccagnoli, and W.M. Cohen, 2002, ' $R \& D$ and the Patent Premium,' Carnegie Mellon University, mimeo.

Arundel, A. and C. Bordoy, 2002, Patenting and Licensing by Dutch Public Research Organisations' (conducted for the Ministry of Economic Affairs), Maastricht, The Netherlands: MERIT.

Arundel, A., C. Bordoy, and M. van der Steen, 2003, 'Knowledge Flows from Dutch Research Organizations to Business Firms,' in Central Bureau of Statistics (CBS), Kennis en Economie 2002 [Knowledge and Economics], Voorburg, The Netherlands, pp. 146-156.

Association of University Technology Managers (AUTM), 1998, Licensing Survey Summary, Norwalk, CT: AUTUM.

Audretsch, D.B. and P. Stephan, 1996, 'Company Scientist Locational Links: The Case of Biotechnology,' American Economic Review 86, 641-652.

Biopartner, 2002, The Netherlands Life Sciences Sector Report 2002, Ede: The Netherlands.

Bozeman, B., 2000, 'Technology Transfer and Public Policy: A Review of Research and Theory,' Research Policy 29, 627655.

Bromley, D., 2004, 'Technology Policy,' Technology in Society 26, 455-468.

Casper, S. and R. Whitley, 2004, 'Managing Competences in Entreprenurial Technology Firms: A Comparative Institutional Analysis of Germany, Sweden and the UK,' Research Policy 33, 89-106.

Clarysse, B., A. Heirman, and J.-J. Degroof, 2001, Het fenomeen spin-off in België [The phenomenon of spin-offs in Belgium], Brussels: IWT Observatorium.

Cohen, M.D. and D.A. Levinthal, 1990, 'Absorptive Capacity: A New Perspective on Learning and Innovation,' Administrative Science Quarterly 35, 128-152.

Cohen, W. and S. Merrill, (eds.), 2003, Patents in the Knowledge-based Economy, Washington DC: National Research Council/National Academies Press.

Colyvas, J., M. Crow, A. Gelijns, R. Mazzoleni, R. Nelson, N. Rosenberg, and B. Sampat, 2002, 'How do university inventions get into practice?,' Management Science 48 (1), 61-72.

Coriat, B. and O. Weinstein, 2003, The Organization R\&D and the Dynamics of Innovation, A Sectoral View. ESSY working paper.

Dahl, M.S. and C.O.R. Pedersen, 2003, Knowledge Flows through Informal Contacts in Industrial Clusters: Myths or Realities? DRUID-Working Paper 03-01, Aalborg University.

Di Gregorio, D. and S. Shane, 2003, 'Why do Some Universities generate More Startups Than others?' Research Policy 32, 209-227. 
Enzing, C.M., S. Kern, and A. v/d Giessen, 2003, $R \& D$ samenwerking door de Nederlanse biotechnologie industrie:Uitkomsten van een survey $[R \& D$ cooperation in the Dutch biotech industry: Findings of a survey], Delft The Netherlands: TNO-STB.

Etzkowitz, H., 2002, MIT and the Rise of Entrepreneurial Science, London UK: Routledge Press.

Etzkowitz, H., 2003, 'Public Venture Capital: The Secret Life of US Science Policy,' in S. Borras and P. Biegelbauer (eds), Innovation Policies in Europe and the US; The New Agenda, United Kindom: Ashgate Aldershot.

European Commission, 2002, Report from the Commission to the European Parliament and Council, 'An assessment of the implications for basic engineering research of failure to publish, or late publication of, papers on subjects which could be patentable', $\operatorname{COM}(2002) 2$ final.

Feldman, M. and P. Descrochers, 2003, 'Research Universities and Local Economic Development: Lessons from the History of the Johns Hopkins University,' Industry and Innovation 10, 5-24.

Galama, J., 2000, Expert Opinion on the Case for and Against the Introduction of a Grace Period in European Patent Law, Submitted on request of the European Patent Organisation.

Gilsing, V.A. and B. Nooteboom, 2006, 'Exploration and Exploitation in Innovation Systems, the Case of Pharmaceutical Biotechnology,' Research Policy 35, 1-23.

Goldfarb, B. and M. Henrekson, 2003, 'Bottom-Up versus TopDown Policies Towards the Commercialization of University Intellectual Property,' Research Policy 33, 639-658.

Graham, S. and D. Mowery, 2003, 'Intellectual Property Protection in the U.S. Software Industry,' in Patents in the Knowledge-based Economy, Washington DC: National Research Council/The National Academies Press.

Henderson, R., A. Jaffe, and M. Trajtenberg, 1998, 'Universities as a Source of Commercial Technology: A Detailed Analysis of University Patenting 1965-1988,' Review of Economics and Statistics 80, 119-127.

Hsu, D. and T. Bernstein, 1997, 'Managing the University technology Licensing Process: Findings from Case Studies,' Journal of the Association of University Technology Managers $\mathbf{9}, 1-33$.

Jaffe, A., R. Henderson and M. Trajtenberg, 1993, 'Geographic Localization of Knowledge Spillovers as Evidenced by $\mathrm{Pa}$ tent Citations,' Quarterly Journal of Economics 108, 577598.

Jaffe, A. and J. Lerner, 2001, 'Reinventing Public R\&D: Patent Policy and the Commercialization of National Laboratory Technologies,' RAND Journal of Economics 32 (1), 167198.

Jaffe, A., 2000, 'The U.S. patent System in Transition: Policy Innovation and the Innovation Process,' Research Policy 29, 531-557.

Jensen, R. and M. Thursby, 2002, 'Proofs and Prototypes for Sale: The Tale of University Licensing,' American Economic Review 91 (1), 240-260.

Kenney, M. and W. Goe, 2004, 'The Role of Social Embeddedness in Professional Entrepreneurship: A Comparison of Electrical Engineering and Computer Science at UC Berkeley and Stanford,' Research Policy 33, 691-707.
Kortum, S. and J. Lerner, 1999, 'What is Behind the Recent Surge in Patenting?,' Research Policy 28, 1-22.

Lanjouw, J. and J. Lerner, 2001, 'Tilting the Table? The Use of Preliminary Injunctions,' Journal of Law and Economics 44 (2), 573-603.

Link, A., J. Scott, and D. Siegel, 2003, 'The Economics of Intellectual Property at Universities: An Overview of the Special Issue,' International Journal of Industrial Organization 21, 1217-1225.

Malerba, F. and S. Breschi, 1997, 'Sectoral Innovation Systems: Technological Regimes, Schumpetarian Dynamics and Spatial Boundaries,' in C. Edquist (eds), Systems of Innovation, Technologies, Institutions and Organizations, London: Pinter.

Mansfield, E. and J.-Y. Lee, 1996, 'The Modern University: Contributor to Industrial Innovation and Recipient of Industrial R\&D Support,' Research Policy 25, 1047-1058.

Markman, G., P. Gianiodis, P. Phan, and D. Balkin, 2004, 'Entrepreneurship from the Ivory Tower: Do Incentive Systems Matter?' Journal of Technology Transfer 29, 353-364.

Matkin, G., 2001, 'Spinning off in the United States: Why and How?,' in STI Special Issue on Fostering High-Tech Spinoffs: A Public Strategy for Innovation, Vol. 26, Paris: OECD.

McKelvey, M. and L. Orsenigo, 2004. 'Pharmaceuticals as a Sectoral Innovation System,' in: F. Malerba (ed.), Sectoral Systems of Innovation, Cambridge University Press.

Merges, R., 1997, Patent Law and Policy: Cases and Materials, 2nd ed, Charelottesville VA: The Mitchie Company.

Ministry of Economic Affairs, 2001, Over de rol van intellectueel eigendom in de Nederlandse kenniseconomie [Concerning the Role of Intellectual Property in the Dutch Knowledge Society], The Hague.

Ministry of Economic Affairs, 2003a, In Action for Innovation; How to Approach the Lissabon Ambition, part 1-3, The Hague.

Ministry of Economic Affairs, 2003b, Researchers op ondernemerspad, Internationale benchmarkstudie naar spin-offs uit kennisinstellingen [Researchers on the Entrepreneurial Path, International Benchmark for Spin-offs from Knowledge Institutions], EZ Beleidsstudies 2, The Hague.

Ministry of Economic Affairs, 2004, Investing in Research and Innovation; Realizing the Potential of Public-Private Interaction, Report summarizing the results of the Conference, held in Noordwijk on 12 and 13 October 2004, The Hague.

Mowery, D., R. Nelson, A. Ziedonis, and B. Sampat, 2004, The Bayh-Dole Act and the Commercialization of University Research, Stanford University Press.

Mowery, D., R. Nelson, B. Sampat, and A. Ziedonis, 2001, 'The Growth of Patenting and Licensing by U.S. Universities: An Assessment of the Effects of the Bayh-Dole act of 1980,' Research Policy 30, 99-119.

Nelson, R.N., 2001, 'Observations on the Post Bayh-Dole Rising of Patenting at American Universities,' Journal of Technology Transfer 26, 13-19.

Nerkar, A. and S. Shane, 2003, 'When Do Start-Ups that Exploit Patented Academic Knowledge Survive?' International Journal of Industrial Organization 21, 1391-1410. 
Nooteboom, B., 2000, Learning and Innovation in Organizations and Economies. Oxford University Press.

NOWT, 2000, Wetenschaps- en technologie indicatoren [Science and Technology Indicators], Leiden/Maastricht, The Netherlands: CWTS/Merit.

OECD, 2002, Benchmarking Industry-Science Relationships, Paris.

OECD, 2003, Turning Science into Business: Patenting and Licensing at Public Research Organisations, Paris.

Oliver, A.L., 2004, 'Biotechnology Entrepreneurial Scientists and their Collaborations,' Research Policy 33, 583-597.

Pavitt, K., 1984, 'Sectoral Patterns of Technical Change: Towards a Taxonomy and a Theory,' Research Policy 13, 141156.

Phillips, R., 2002, 'Technology Business Incubators: How Effective as Technology Transfer Mechanisms?' Technology in Society 24, 299-316.

Pisano, G., 2002, 'Pharmaceutical Biotechnology,' in B. Steil, D.G. Victor and R.R. Nelson (eds.), Technological Innovation and Economic Performance, Princeton University Press.

Porter, M., 1990, The Competitive Advantage of Nations, London: Macmillan.

Porter, M.E., 1998, On Competition, Boston, MA: Harvard Business School.

Rothwell, R., 1983, 'Innovation and Firm Size: A Case for Dynamic Complementarity - Or is Small Really so Beautiful?' Journal of General Management 8, 5-25.

Senter, 2001, Geld voor kennisinstelling en spin-offs [Funds for Knowledge Institutes and Spin-offs], The Hague.

Sherry, E. and D. Teece, 2004, 'Royalties, Evolving Patent Rights, and the Value of Innovation,' Research Policy 33, 179-191. van der Steen, M., 1999, Evolutionary Systems of Innovations, The Netherlands: Van Gorcum.

van der Steen, M., 2003, 'Technology Policy learning The Netherlands 1979-1997,' in S. Borras and P. Biegelbauer (eds), Innovation Policies in Europe and the US, The New Agenda, United Kingdom: Ashgate Aldershot.

Teece, D., 1986, 'Profiting from Technological Innovation: Implications for Integration, Collaboration, Licensing and Public Policy,' Research Policy 15, 285-305.

Utah Technology Alliance, 2001, A Guide to Utah's Technology Landscapes', Utah.gov/tech.

Van der Sijde, P.C. and J.J. van Tilburg, 2000, 'Support of University Spin-off Companies,' International Journal of Entrepreneurship and Innovation 1, 13-22.

Wintjes, R., J. van Tilburg, P. van der Sijde, and M. Hocke, 2002, Spin-offs uit kennisinstellingen: Een vergelijkend literatuuronderzoek' [Spin-offs of Knowledge Institutions. A Comparative Literature Survey]. Report commissioned by the Dutch Ministry of Economical Affairs.

Wright, M., S. Birley, and S. Mosey, 2004, 'Entrepreneurship and University Technology Transfer,' Journal of Technology Transfer 29, 235-246.

Ziedonis, R., 2003, 'Patent Litigation in the U.S. Semiconductor Industry,' in W. Cohen and S. Merrill (eds), Patents in the Knowledge-based Economy, Washington DC: National Research Council, The National Academies Press.

Zucker, L.G., M.R. Darby, and Y. Peng, 1998, 'Fundamentals or Population Dynamics and the Geographic Distribution of U.S. Biotechnology Enterprises, 1976-1989,' NBER Working Papers 6414, National Bureau of Economic Research. 